\title{
Misadventure in Muirhouse. HIV infection: a modern plague and persisting public health problem
}

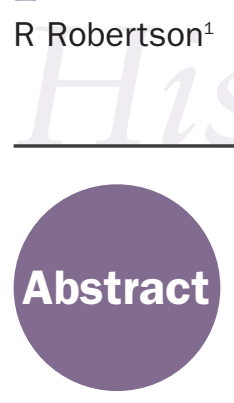

This story is of particular interest and importance to Edinburgh and Scottish medicine. It describes the events in one general medical practice in Edinburgh, the Muirhouse Medical Group, and their impact and relationship to the AIDS pandemic. For many, the origin of HIV in the UK is now history. Since the introduction of HIV/AIDS into the intravenous illegal drug using community, much has changed but problems remain that should concern policy makers and clinicians. Reflections on the recent history of the HIV epidemic among drug users in the UK provide important insights into risks for current policy making and the potentially problematic direction that policy has taken. Rather than starting from a pragmatic baseline of harm minimisation, with its low cost, high impact, prevention approach, the emphasis, and consequently the resources, has been on a model of recovery which fails to acknowledge the fragile control maintained by early intervention and supporting treatments.

In 2015, the re-emergence of HIV in a vulnerable inner city population of people who inject drugs highlighted a policy failure. An ongoing epidemic could and should have been prevented, as should several other recent epidemics of other viral or bacterial infections in urban populations in Scotland.

The story of HIV is full of controversy, denial, prejudice and stigma. At all levels across the world from national presidents, governments and public opinion, progress has been impeded by these problems. People using drugs have an additional set of problems: criminality, poverty and marginalisation from education and the supports of main stream society. These continue to hamper efforts to improve lives and prevent disease

Keywords AIDS, drug injecting, epidemic, HIV, people who inject drugs

Declaration of interests No conflict of interests declared

\section{Correspondence to:} R Robertson Muirhouse Medical Group 1 Muirhouse Avenue Edinburgh EH4 4PL UK

Email:

roy.robertson@ed.ac.uk

\section{Background and introduction}

The story of the introduction of HIV into the Scottish drug injecting population in 1982 was revealed in a landmark publication in the British Medical Journal in $1986 .{ }^{1}$ This publication reported on results of testing for the human immunodeficiency virus (then known as HTLV3) in a population of young people who injected heroin in Edinburgh. This was a ground-breaking discovery, the significance of which was not fully apparent at the time and the consequences of which were to emerge over the subsequent few years. Several things make it worth reporting on this now and reflecting on its significance and the impact of this discovery on subsequent events.

Public health policy on management of drug users went through a seismic shift in 1986 when it became apparent that HIV was spreading in this population. A state of urgent assessment and intense political activity adjusted over the subsequent few years to accommodate a profound change in approach to the treatment of drug using people, alongside an extraordinary revision of official and public knowledge of the reality of drug use and sexual behaviour. Institutional memory is, however, variable and the early years of the $21 \mathrm{st}$ century have allowed for slippage in prevention initiatives and understanding, giving rise to a further epidemic of HIV in Scottish drug users. New situations and potential risk behaviours include the drug-related sexual behaviour in some groups described as 'chemsex'. This is associated with an increased risk of transmission of blood borne viruses. ${ }^{2}$

Previous epidemics of hepatitis $B$ had been described in the late 1970 s but the low level of interest in drug users, the perception of a low risk to the rest of the population and the relatively small morbidity and mortality rates allowed for a 
complacent neglect of this warning sign. ${ }^{3}$ Interestingly hepatitis $B$ and its risk outside the sentinel group was of more interest in Edinburgh where a small outbreak of hepatitis B in the renal unit of the Royal Infirmary had caused deaths among medical and nursing staff. ${ }^{4,5}$

\section{Hepatitis B epidemics in the 1960s and 1970s}

From the early 1960s renal dialysis was becoming increasingly popular in centres across the UK and renal transplantation was developing. Hepatitis B, however, emerged in several centres causing alarm and serious mortality among patients and staff. The 'Australia antigen' had been identified in 1966 and the test for it became widely available in 1969.

In Manchester in 1965, 50 people were affected, and in Edinburgh in 1969, 26 dialysis patients were affected and seven died. Twelve members of staff were also infected, four of whom died ( two transplant surgeons and two technicians). In the same year the European Renal Registry recorded that 499 members of staff contracted hepatitis across 568 reporting renal units in Europe, with 12 deaths. ${ }^{6,7}$

This had a profound effect on staff and students in Edinburgh for many years.

\section{The epidemic of HIV among people who injected drugs in 1982-1984}

The 1986 research paper ${ }^{1}$ identified the presence of HIV, in epidemic phase, for the first time in the UK. Apart from the impact on those young people at risk from drug injecting, this epidemic was significant because it represented a possible entry of HIV into the heterosexual population and therefore the potential for an African-style epidemic.

It is known now that the introduction of the virus to the drugusing population in Edinburgh and Dundee, from an unknown source, happened in 1982. This was discovered from stored samples taken during a study of a prior epidemic of hepatitis $B$ infection (and undiagnosed hepatitis $C$ ) in this group of young injecting drug users. The delay in identifying the presence of the HIV virus in this population came about as a result of the long period between infection and the onset of symptoms and in the absence of a clinical test that would identify the presence of the virus. An invisible epidemic was happening in this population of drug users and at the same time in other at-risk populations.

The delay between transmission and onset of symptoms was one of the defining elements of the global AIDS epidemic in its early stages, before the introduction of a test. By the time of the discovery of the, then named, LAV/HTLV3 virus, by French and American researchers, the virus was present in the Edinburgh drug user population, as it was in several hundred thousand other people in Western Europe and North America, and several million in Africa.

All this changed in 1986 which was the year testing was carried out on a population scale and clusters of, as yet asymptomatic, cases were discovered. Scotland, or more particularly Edinburgh and Dundee, was found to have a cryptic HIV presence in a population of young people who had contracted the virus during an epidemic of heroin use and equipment sharing between 1981 and 1984. Intriguingly, Glasgow, with a larger drug using population, was spared any HIV infection.

Surveillance data from the public health laboratory service in Colindale showed how recently HIV/AIDS had been introduced into the UK. By the end of 1985 only seven cases of AIDS had been reported to the national database. By the end of 1985, when the test became available, 55 reports of HIV antibody positive tests were recorded in England and Wales and 356 in Scotland. ${ }^{8}$

\section{Heroin availability in Western European cities on an unprecedented scale}

The epidemic of heroin use in Scotland in the early 1980s was part of a wave of drug-taking that swept Western Europe when availability of heroin reached many places with little history of opiate use. International events including the Russian invasion of Afghanistan and the Islamic revolution had stimulated an unprecedented supply to the West. The subsequent reckless behaviour excellently enshrined in Irvine Welsh's book and film Trainspotting is familiar to many people working in drug services in most European cities. ${ }^{9}$ Similar epidemics among populations of young, inexperienced, heroin injectors were unfolding in other European cities such as Dublin and Milan, where prevailing conditions and inadequate public health responses had failed to recognise the risks of disenfranchised inner city groups. The UK Government of the day was slow to recognise the problem and reluctant to engage drug users in appropriate treatment. Similarly the guidance documents at the time recommended minimal opiate substitute prescribing and resourced a non-medical social rehabilitation style of treatment agency. ${ }^{10,11}$

In 1986, most cases among the drug using population were HIV antibody positive rather than at the stage of showing symptomatic HIV or advancing AIDS. Edinburgh, therefore, had some time to assemble a response and to consider the risk to the heterosexual population before clinical cases emerged. Identifying the presence of HIV in drug using populations in 1986 caused considerable concern to clinicians as well as patients and the public as little was understood about infectivity and as a result anxiety spread rapidly. Two other important publications had special significance in 1986 and 1987 . The first of these was the description of the lack of casual household transmission of HIV in the absence of sexual contact. ${ }^{12}$ This clearly showed that risks of transmission were likely to be confined to sexual or blood-to-blood exposure and was an immensely important finding for many people working with cases of HIV and AIDS. The second was the publication of data from sero-discordant heterosexual couples showing no transmission of HIV in those who had not also shared injecting equipment. With these two pieces of the jigsaw, a better idea of risk factors became clear. A subsequent study of partners of known positive drug users was conducted in collaboration with the Middlesex Hospital. ${ }^{13}$ This showed, in contrast to what was happening in Africa, an almost total absence of transmission 
to heterosexual partners, a finding with enormous public health importance.

Over the next few years, and with a better understanding of the incubation period of HIV infection, cases emerged in Edinburgh and people died in an increasingly familiar pattern of a wasting disease associated with a wide range of opportunistic infections. Lung infections including Pneumocystis carinii pneumonia, immunological failure leading to fungal infections, distressing eye conditions, fatigue and organ failure become commonplace. Selfmedicating with legal and illegal drugs becamse the norm.

Prevention in the form of education and harm reduction for people using drugs developed rapidly and lessons of needle exchange and methadone maintenance treatment were learned from Amsterdam, Milan, Dublin and Madrid. The 'McClelland report', published by the Scottish Home and Health Department in 1986, was probably the first national endorsement of these provisions. ${ }^{14}$

Other landmarks in the AIDS/HIV story in the intervening period included the sexual behaviour in the UK survey, ${ }^{15}$ which updated our understanding of sexual behaviour from the Kinsey reports of the 1950 s, ${ }^{16,17,18}$ the descriptions of the limited likelihood of heterosexual transmission in Western countries, the discovery and availability of antiviral chemotherapy for HIV infection in 1996, and the global treatment and prevention campaigns.

In the understanding of drug user behaviour and how best to intervene and support preventative measures, the seminal developments have been: making injecting equipment available (although this is far from universal and runs a constant risk of underfunding), the waxing and waning of availability of heroin for injecting, the damaging tensions in understanding of the effectiveness and importance of long term treatment with opiate substitutes, and the diversification of drugs with the advent of synthetic substances and the availability of online supplies.

Stories can be written as events unfold or from a perspective of history. The advantage of retrospect is that context and continuity are clearer and the consequences of actions may be apparent. 19, 20, 21, 22 Contemporary accounts, however, may allow a greater insight and vitality to a situation. It is hard to believe that as recently as 1980 sexual behaviour was poorly understood and that there had been little research since Kinsey in the 1950s. This was to change rapidly over the first few years of the HIV/AIDS epidemic.

\section{Important events and influences affecting policy in Scotland and the UK during early years of the epidemic}

Contributions to the UK and, for the purpose of this paper, the Scottish experience, of HIV came from many sources. From the USA, an extraordinary epidemiologist, Andrew Moss, spent many months in Scotland advising government and clinicians of the scale and scope of the problem and the potential for further expansion of the epidemic, apparently confined at the time of discovery in 1986 to injecting drug users, to the heterosexual community. Warning of political inertia he drew attention to events in California and the fact that although 20,000 Americans had already died of HIV by May 1987, President Reagan had been reluctant to make a public statement on the epidemic. In the UK the spectre of a heterosexual epidemic generated by the young drug using population energised officials and clinicians in an attempt to implement emergency public health interventions. Without this insight and Andrew Moss' charismatic and visionary leadership, the inevitable inertia of a government in Westminster, with an indifferent attitude to drug dependents, the delay would have been greater. The exceptions to a blind Westminster administration were Norman Fowler (the Minister for Health) and William Whitelaw (the deputy Prime Minister), the former after a visit to a San Francisco devastated by its own epidemic and the latter with a skilful hand on the Prime Minister of the day.

Peter Selwyn, Gerald Friedland and their dedicated colleagues worked through a decade of HIV caseload in the Bronx without knowing the cause of AIDS or, indeed, the incubation period or degree of infectivity. Selwyn's descriptions of his experiences are beautifully described in his book which encapsulated the enormity of the events of the 1980s. ${ }^{23}$ Alex Wodak, from Sydney, has spent 30 years travelling to all parts of the world to educate colleagues and to challenge poor public health policy, sometimes in the most hostile political climates. Bob Newman has researched, educated and committed himself to more than a normal length of career to espouse the health and lifesaving benefits of methadone. This dedication must have saved countless lives and, equally important, have rescued many from despair. Don Des Jarlais had a singularly important role over the subsequent 20 years in defining the epidemiology of the global epidemic. Rae Brettle, in Scotland, pioneered, against enormous resistance, the total care of a hugely disadvantaged and misunderstood population of people dying of HIV infection. Anne Johnston led a series of research and educational initiatives which helped to transform the understanding and practice of sexual behaviour. Sheila Bird has worked tirelessly to describe and quantify the impact of blood borne virus infection in the UK. Jonathan Mann founded the WHO's Global Programme for AIDS in 1986 but resigned in 1990 to protest at the lack of response from the United Nations with regard to AIDS.

\section{International HIV/AIDS Conferences as a barometer of progress}

The ebb and flow of information and changes in the fortunes of HIV research and treatment are reflected in the titles and topics of the, now biennial, International AIDS Conferences. Always a barometer of the expectation and outlook for populations and individuals with HIV, the Conference themes present a regular update. The early Conferences in Atlanta (1985), Paris (1986) and Washington (1987) described the understanding of the epidemiology and distribution of the virus in the USA, Europe and the poor understanding of the extent to which HIV was penetrating vast populations in Africa. In 1986, the Director of Social Work from Soweto was asked about HIV in Johannesburg when he visited Edinburgh to discuss the Scottish response to the crisis. He expressed the belief that there was none and added that he did not 
HIV, drug related and liver disease deaths

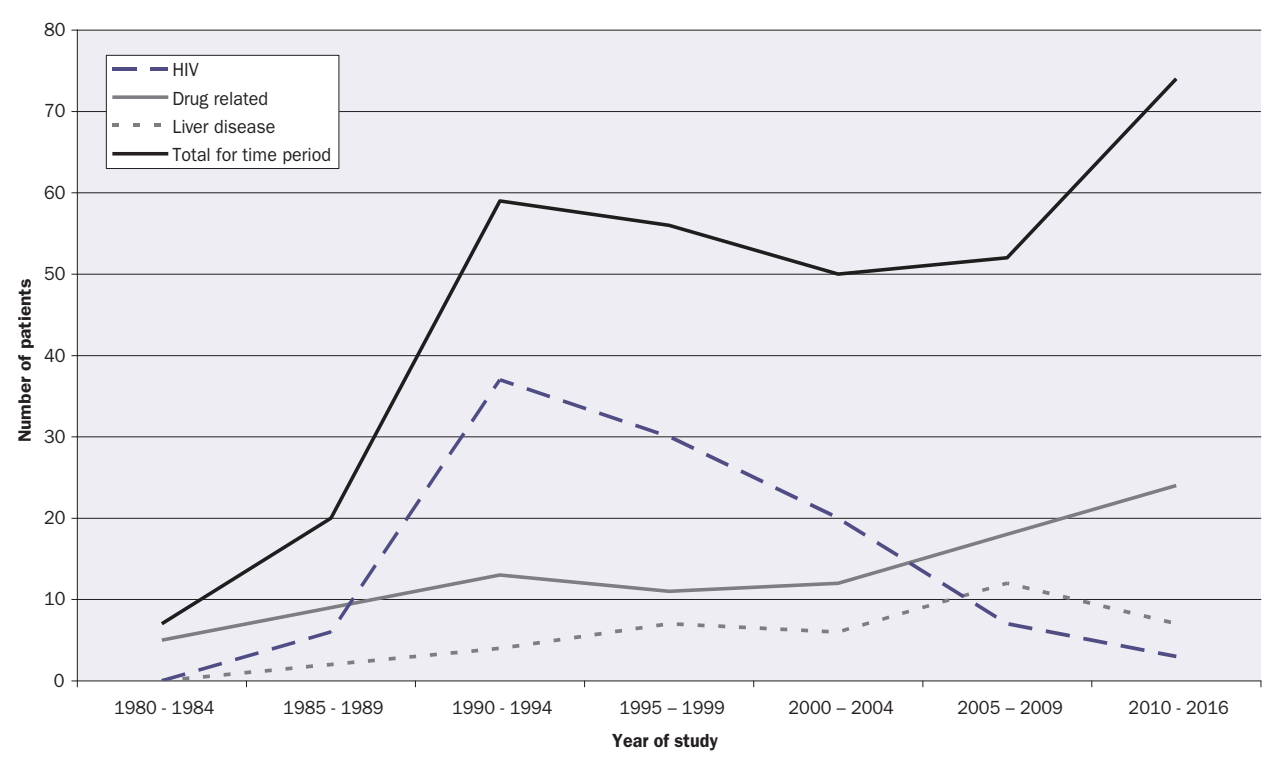

Figure 1. Changes in HIV, drug related and liver disease deaths over time (shows increase in drug-related deaths)

Graph based on 318 deaths where causes are known need to test because it was not there. Sad to think that along with a prolonged period of denial by government this was a lost opportunity to intervene early in an epidemic that has caused devastation for South Africa.

The 1988 Conference (Stockholm, theme 'The Face of AIDS') concerned itself with groups other than the men who have sex with men and focused, a little, on injecting drug users, heterosexuals and developing countries, particularly Africa. The extent of the global problem was becoming clearer.

After a decade of bad news, better understanding of the global risk and impact, the 1996 Conference in Vancouver, theme 'One World, One Hope', presented the new antivirals and heralded a new era and a potential triumph for medicine in conquering AIDS. This in many ways represented the beginning of a new era in HIV treatment and is reflected in the Edinburgh cohort in which deaths from AIDS rapidly declined (Figure 1).

The 2000 Conference in Durban was the first in a developing country and held out some hope, and a major setback. The theme was 'Breaking the Silence' and focused on revealing the staggering impact of HIV in sub-Saharan Africa. The disappointment came from the South African President, Thabo Mbeki, who declared he doubted that AIDS occurred in South Africa and that it was not caused by HIV but by poverty. In contrast at the 2004 Conference in Bangkok, Thai Prime Minister, Thaksin Shinawatra, surprised the Conference by pledging to adopt a 'harm minimization' approach to AIDS prevention. It was a surprise because until then his Government had been known, like others, to take a harsh line with drug users.

Optimism continued to be the preferred presentation of successive Conferences with the themes being 'Commitment for Action' (Vienna 2010), 'Turning the Tide Together' (Washington 2012) and 'Stepping up the Pace' (Melbourne 2014). Ahead of the Vienna conference, however, it was felt necessary to issue a statement which became known as the
Vienna Declaration. This was an international call for drug policy to be based on science, not ideology. By the end of the Conference the declaration was signed by 12,725 individuals.

At the 2016 Conference in Durban, however, there was a muted theme reflecting a decrease in belief that the global AIDS burden is on the downturn; 'Access Equity Rights Now' was the theme. The rising understanding of the devastating impact of drug use as a vector of HIV in Asia was in many sectors a great concern.

\section{Conclusions and observations}

Although African and Asian epidemics of HIV among injecting drug users are a bigger story beyond the scope of this paper, the global AIDS epidemic remains an emerging story; the impact of which will only be fully apparent in decades to come when the expectation of spread in Asian countries and Russia becomes a clinical reality. It has become increasingly evident that a significant proportion of the caseload of HIV/AIDS has been due to injecting drug use in countries that have failed to learn from the lessons and policy failures of the West. Observing the political, one step forward and two steps back, of North America and Europe it may be hardly surprising that effective drug policy seems to require a crisis before public health intervention is politically possible. The present day situation is hard to summarise in a short paper, but Scotland is currently experiencing another epidemic of HIV transmission in injecting drug users, this time in Glasgow, thus demonstrating the continued vulnerability of this group. Glasgow has had mixed fortunes over the last few decades. The health and social consequences of poverty in a postindustrial environment has been striking. ${ }^{24,25}$ Despite best efforts hepatitis $C$ is again increasing among drug users and clusters of anthrax, Clostridium infections and deaths continue to give concern.

Drug policy remains controversial and treatment services are, once again in 2017, under stress from savings in the face of a shrinking economy, a pattern of political and policy events 
Figure 2. HIV, drug related and liver disease deaths in the Muirhouse cohort

Causes of death in EAC by time periods

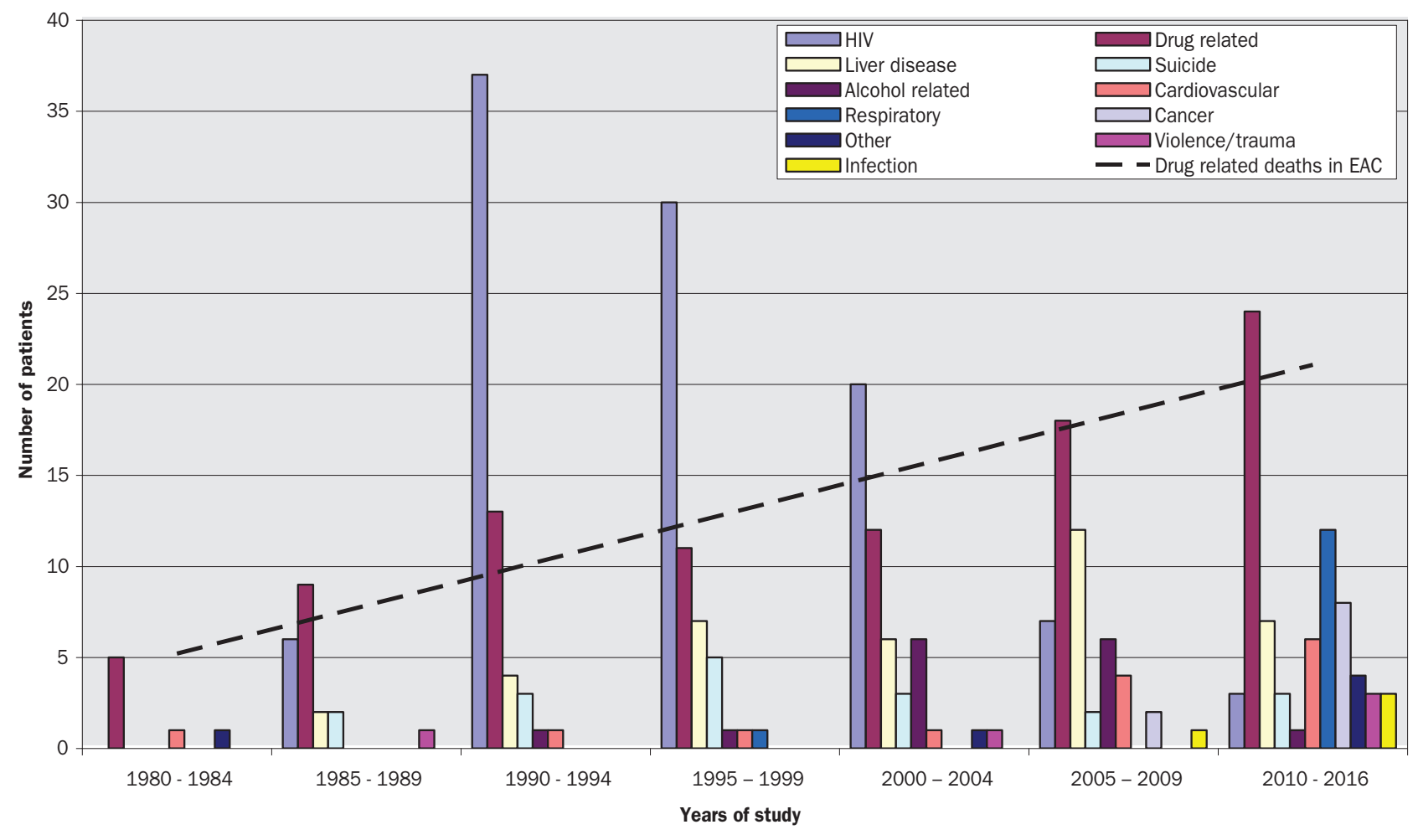

strikingly similar to those of the early 1980s. Drug users remain one of societies' victims and institutional prejudice and stigma continue to allow their management to be reluctant and minimalistic. A better understanding of the reasons why people use drugs and attempts to redefine addiction as self-medication, often for a very good reason, has, sadly, failed to raise the importance of the damage inflicted by drug use in the realms of other diseases. A longterm follow up study of the Edinburgh cohort has established further the devastating impact that drug use and HIV/AIDS has had in this group and the requirement for long term support for most of those surviving. ${ }^{26,27}$

As might be expected, mortality and morbidity in an ageing cohort will reflect cumulative and age-related influences. Deaths from drug use continue but are added to by the longer term effects of smoking and changing vulnerabilities to drugs. ${ }^{28}$ Figure 2 represents the emerging cardiovascular, respiratory, liver and other causes noted on death certificates, representing the multi-morbid state of an ageing caseload.
Although drugs policy has been progressive in the UK, the fickle nature of politics results in unpredictability which leads to unintended consequences, ${ }^{29,30}$ often hardest on those with poorly understood mental health problems. There is no complete policy or scientific solution to an existential crisis like addiction but a compassionate society must accommodate individual choice, recognise vulnerability and the reasons behind drug use and resource mainstream health and social care agencies at an unprecedented level.

\section{Acknowledgements}

I apologise to those who have been omitted but whose contribution has been significant in the exploration of the lives and misfortunes of people using drugs over the last 30 years. The partners and staff, past and present, of the Muirhouse Medical Group deserve a special mention. Their unquestioning commitment to their colleagues and patients has been a privilege to share. 


\section{References}

1 Robertson JR, Bucknall ABV, Welsby PD et al. Epidemic of AIDSrelated virus (HTLV-III/LAV) infection among intravenous drug abusers. BMJ 1986; 292: 527-9.

2 Macfarlane A. Sex, drugs and self-control: why chemsex is fast becoming a public health concern. J Fam Plann Reprod Health Care 206; 42: 291-4.

3 Bewley TH, Ben-Arie O, Marks V. Morbidity and mortality from heroin dependence. 3. Relation of hepatitis to self-injection techniques. $\mathrm{Br}$ Med J 1968; 1(5594): 730-2.

4 Douglas C. The Houseman's Tale. BMJ 2011; 343: d4593.

5 Marmion BP, Burrell CJ, Tonkin RW et al. Dialysis-associated hepatitis in Edinburgh; 1969-1978. Rev Infect Dis 1982; 4: 619-37.

6 Infection risks of haemodialysis - some preventive aspects. A Report to the Public Health Laboratory Service by the Working Party on Haemodialysis Units. Br Med J 1968; 3: 454-60.

7 Ringertz 0, Melén B. Hepatitis and the artificial kidney. Lancet 1966; 287: 151.

8 Robertson R. The Arrival of HIV In: Strang J. Gossop M, editors. Heroin Addiction and Drug Policy. The British System. Oxford: Oxford University Press; 1994. p.91-9.

9 Welsh I. Trainspotting. London: Secker and Warburg; 1993.

10 Treatment and Rehabilitation. Report from the Advisory Council on the Misuse of Drugs. Home Office. London; 1984.

11 Guidelines of Good Clinical Practice in the Treatment of Drug Misuse. Report of the Medical Working Party on Drug Dependence. London: DHSS; 2017, in press.

12 Friedland GH, Saltzman BR, Rogers MF et al. Lack of transmission of HTLV-III/LAV infection to household contacts of patients with AIDS or AIDS-related complex with oral candidiasis. N Engl J Med 1986; 314: 344-9.

13 Downs AM, De Vincenzi I et al. Probability of heterosexual transmission of HIV: relationship to the number of unprotected sexual contacts. J Acquir Immune Defic Syndr Hum Retrovirol 1996; 11: 388-95.

14 McClelland Report 1986. Edinburgh: Scottish Home and Health Department.

15 Johnson AM, Petherick A, Davidson SJ et al Transmission of HIV to heterosexual partners of infected men and women. AIDS 1989; 3: 367-72.

16 Bancroft J. Sexual behaviour in Britain and France. BMJ 1992; 305: 1447-8.

17 Kinsey A, Pomeroy WB, Martin CE et al. Sexual Behaviour of the Human Female. Philadelphia: WB Saunders; 1953.

18 Kinsey AC, Pomeroy WB, Martin CE. Sexual Behaviour in the Human Male. Philadelphia: WB Saunders; 1953.
19 Skidmore CA, Robertson JR, Robertson AA et al. After the epidemic: follow up study of HIV seroprevalence and changing patterns of drug use. BMJ 1990; 300: 219-23.

20 Burns SM, Brettle RP, Gore SM et al. The epidemiology of HIV infection in Edinburgh related to the injecting of drugs: an historical perspective and new insight regarding the past incidence of HIV infection derived from retrospective HIV antibody testing of stored samples of serum. J Infect 1996; 32: 53-62.

21 Wyld R, Robertson JR, Brettle RP et al. Absence of hepatitis C virus transmission but frequent transmission of HIV-1 from sexual contact with doubly-infected individuals. J Infect 1997; 35: 163-6.

22 Robertson JR, Richardson A. Heroin injecting and the introduction of HIV/AIDS into a Scottish city. J R Soc Med 2007; 100: 491-4.

23 Selwyn PA. Surviving the Fall: The Personal Journey of an AIDS Doctor. New Haven, CT: Yale University Press; 1998.

24 McGuigan CC, Penrice GM, Gruer L et al. Lethal outbreak of infection with Clostridium novyi type $A$ and other spore-forming organisms in Scottish injecting drug users. J Med Microbiol 2002; 51: 971-7.

25 National Anthrax Outbreak Control Team. An Outbreak of Anthrax Among Drug Users in Scotland, December 2009 to December 2010. Health Protection Scotland, 2011. http://www.hps.scot.nhs.uk/giz/ anthraxoutbreakdecember2009december2010.aspx

26 Kimber J, Copeland L, Hickman M et al. Survival and cessation in injecting opiate users, a prospective observational study of outcomes and the effect of opiate substitute treatment. BMJ 2010; 340: c3172.

27 Xia Y, Seaman S, Hickman M et al. Factors affecting repeated cessations of injecting drug use and relapses during the entire injecting career among the Edinburgh Addiction Cohort. Drug Alcohol Depend 2015, 151; 76-83.

28 Degenhardt L, Bucello C, Mathers B et al. Mortality among regular or dependent users of heroin and other opioids: a systematic review and meta-analysis of cohort studies. Addiction 2011; 106 : 32-51.

29 Mold A. Heroin: The Treatment of Addiction in Twentieth-Century Britain. DeKalb, IL: Northern Illinois University Press; 2008. p.246.

30 Strang J, Gossop M. Heroin Addiction and Drug Policy. The British System. Oxford: Oxford University Press; 1994. 